of such men as Scheuchzer and Derham. We are told that Lambert in Germany seems to have been the first to present meteorological data in the form of graphs rather than in tables; but such plotting can be found half a century earlier-for example, by Cruquius, showing the course of a year's observations of pressure (Phil. Trans. R.Soc. 33 (no. 381), 1724).

Halley's approach to global meteorology (1686) on the trade wind circulation is appropriately discussed and his celebrated map is reproduced (pp1267 ); it sems supererogatory to show the evident copy of Halley's map that was published by d'Alembert (p131). There are some infelicities: strata is a plural on p16, but is used as a singular on p17; on p3 some may question the phrase "the cyclic movement of water falling from the sky in the form of rain and condensing back into the sky"; and on p78 work by Hooke is wrongly ascribed to Trans. R. Soc. Edin. long before it was founded.

There is admirable provision of references for those who wish to go further, and many welcome illustrations, notably that of Wren's weather clock. As a short history, the book is agreeable as far as it goes, although the author's commendable regard for the dynamic aspects together with his evident effort at brevity has led to the omission of a good deal that is germane to the evolution of the science as it stood in 1800

Gordon Manley was Professor of Environmental Sciences at the University of Lancaster from 1964-68.

\section{Gap junctions and chemical synapses}

Receptors and Recognition. Series B. Vol. 2: Intercellular Junctions and Synapses. Edited by J. D. Feldman, N. B. Gilula and J. D. Pitts. Pp. 246 (Chapman and Hall: London, 1978.) £15.

THIS book sprang from a highly successful meeting organised in 1976 by one of the Editors, J. D. Feldman, and covers the two main major areas of interest at that meeting: gap junctions and chemical synapses.

The fact that the gap junction is still (as Wolpert puts it) "a structure in search of a function" inevitably pervades the first chapters. This is a reflection of the field, rather than the authors, who between them provide a good statement of current knowledge, but few new insights. The chapters either provide relatively straightforward accounts (structure by Gilula; permeability by Bennett) or range widely (growth control by Pitts; developing systems by Wolpert). The latter two chapters encompass those areas in which direct cell to cell communication (probably mediated by gap junctions) can most easily be seen to be necessary.

Even so, experimental evidence that intercellular communication of the type mediated by gap junctions plays an essential role is lacking. It is difficult to agree with Pitts' assertion that junctional permeability has been convincingly shown to be the same in vivo as in vitro. The few experiments which have been done in vivo (cited in another revicw by the same author) do not allow such a general conclusion, because it is not yet possible to do the same kind of experiments in vivo as in vitro. Wolpert presents a more balanced view, perhaps because he is not personally involved in the experimental investigation of gap junctions, yet is concerned with their possible role during early development.

Sheridan brings together information on junction formation from scattered sources. He also takes a careful and critical look at the experiments of Loewenstein and his group on the possible role of calcium in controlling the permeability of the gap junction.

The synapse section begins with a comprehensive review by $\mathrm{A}$. Matus on the present state of the structure of chemical synapses and current progress with isolation of its protein components. J. D. Feldman and C. R. Slater tackle the problem of specificity of synapse formation in completely different ways. Feldman takes a broad overview of the process, drawing freely on an analogy between the neurone searching for its contact and the migrating bird seeking its destination; whereas Slater restricts himself to the more discreet topic of the mammalian neuromuscular junction. They are both, in their different ways, interesting and instructive. The first part of Kelly's chapter on cholinergic processes clearly summarises the present situation, although the relationship between the latter part and the rest of the book is difficult to see.

Should one buy this book? Libraries yes, for it provides a useful introduction for the third-year undergraduatc and newcomer to the field, but I cannot see individuals buying a book which, one hopes, will soon become out of date as research into these two topics advances.

Anne Warner

Anne Warner is Senior Lecturer in Anutomy and Embryology at University' College, London, $U K$.

\section{Mass spectroscopy}

Principles of Field Ionization and Field Desorption Mass Spectroscopy. By H. D. Beckey. Pp. 335. (Pergamon: London and New York, 1978.) £19.50; $\$ 35$.

THIs book was originally intended to be a second edition of the author's Field Ionization Mass Spectrometry which was largely written in 1969. However, developments in the field in subsequent years convinced the author that he should produce an essentially new volume dealing with the subject under five main headings, which appeared to represent the growth areas. These are: theory of field ionisation (FI) and field desorption (FD), experimental methods, kinetics and mechanisms of decomposition of field ions in the gas phase, and qualitative and quantitative analysis with field ionisation and field desorption mass spectrometry.

After dealing with the theory of FI and FD, the next chapter goes on to describe the techniques of FI and FD, and in particular the design and performance of sources. This chapter should be of value to anyone intending to modify a conventional mass spectrometer to encompass these techniques. The advantages and disadvantages of tips, blades and thin wires are discussed in detail. Problems of resolving power and sensitivity are also broached. The third chapter again deals with theory, this time being more concerned with ionic decomposition under high ficld conditions. The energetics of such decompositions is discussed in some detail, and methods of determination of the appearance potentials of fragment ions are reported.

The kinetics of ion decomposition consequent upon $\mathrm{FI}$ form the subject matter of chapter four. This is an area of particular interest, as the time scale of the decompositions can be as short as 10 ps. In particular the normalised rate constant $k(t)$ (sometimes called the phenomenological rate constant) is dealt with in some detail. A number of cxamples are given of the application of the theory to specific unimolecular decompositions.

The final chapter deals with the analytical aspects of $\mathrm{FI}$ and FD mass spectrometry. Applications of the recently developed field of alkali ion attachment are discussed.

This book is a worthy successor to the earlier volume and must have a place on the shelves of any one working or intending to work on FI or FD. There are nearly four hundred references, which should cnable the newcomer to find his way around the field. The only criticism I would make is of the unjustified righthand margins, which I find most distasteful.

Allan Maccoli

Allan Maccoll is Professsor of Chemistry at University College, Lomdon, UK. 